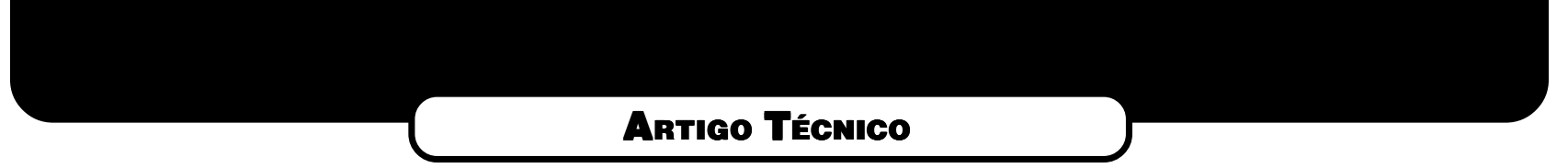

\title{
Caracterização da microfauna em estação de TRATAMENTO DE ESGOTOS DO TIPO LODOS ATIVADOS: UM INSTRUMENTO DE AVALIAÇÃO E CONTROLE DO PROCESSO
}

\section{Microfauna CHARACTERIZATION IN ACTIVATED SLUDGE WASTEWATER TREATMENT PLANT: AN INSTRUMENT OF ASSESSMENT AND CONTROL OF PROCESS}

\begin{abstract}
AlesSandRa PelLIZZARo BENTo
Bióloga e Doutora em Engenharia Ambiental pela Universidade Federal de Santa Catarina (UFSC) com Doutorado Sanduíche na Universidade Técnica de Munique (TUM - Alemanha)

\section{PABLO HELENo SEZERINO}

Engenheiro Sanitarista e Doutorando em Engenharia Ambiental na UFSC
\end{abstract}

\section{LUIZ SERGIO PHILIPPI}

Doutor em Saneamento Ambiental pela Université de Montpellier I (França) e Professor Titular do Departamento de Engenharia Sanitária e Ambiental da UFSC

\section{VALERIA REGINATTO}

Bioquímica pela UFSC. Doutora em Ciências pela UNICAMP com Doutorado Sanduíche na Universidade de Hanover (Alemanha)

\section{FLAVIO RUBENS LAPOLLI}

Engenheiro Civil pela UFSC. Doutor em Engenharia Hidráulica e Saneamento pela USP (São Carlos) e Professor Titular do Departamento de Engenharia Sanitária e Ambiental da UFSC

Recebido: 07/01/05 Aceito: 29/09/05

\section{RESUMO}

A microfauna presente em uma ETE por lodos ativados foi caracterizada, correlacionada com parâmetros físico-químicos e utilizada em modelos existentes de avaliação de sistemas. Durante 351 dias o lodo ativado manteve-se estável com flocos compactos, pequenos e com poucos filamentos. Os protozoários predominantes no lodo foram as tecamebas e os ciliados predadores de flocos, indicando estabilidade do sistema. Os métodos propostos em literatura, baseados no IBL, na densidade total da microfauna e na relação entre ciliados predadores de flocos e ciliados fixos, mostraram-se eficientes para o diagnóstico das condiçôes depurativas do sistema. A análise qualitativa do lodo, englobando o tamanho, quantidade de filamentos, compactação e a identificação das espécies dominantes, foi suficiente para uma caracterização imediata das condições depurativas do sistema de tratamento.

PALAVRAS-CHAVE: Microfauna, lodo ativado, esgoto doméstico, microscopia, diagnóstico do tratamento.

\begin{abstract}
Microfauna found in an activated sludge WTP was characterized, correlated to the physical-chemical parameters and used in existing assessment models. During 351 days, the activated sludge remained stable with compacted and small poorly filamentous flocs. It was composed mainly by testate amoebas and crawling ciliates that indicated the stability of the system. The application of the existent system evaluation models to microfanna (SBI, crawling ciliate) attached ciliate relation and total density) was found to be efficient for the assessment of the system depurative conditions. The sludge qualitative analysis, which included the flocs size, amount of filaments, compacting and the identification of the dominant microfauna species, was enough to an immediate diagnosis of the treatment system depurative conditions.
\end{abstract}

KEYWORDS: Microfauna, activated sludge, domestic wastewater, microscopy, treatment diagnosis 


\section{INTRODUÇÃO}

Os sistemas de tratamento de esgotos por lodos ativados são os mais amplamente empregados no mundo todo, principalmente pela alta eficiência alcançada associada à pequena área de implantação requerida, quando comparado a outros sistemas de tratamento. O princípio do processo baseia-se na oxidação bioquímica dos compostos orgânicos e inorgânicos presentes nos esgotos, mediada por uma população microbiana diversificada e mantida em suspensão num meio aeróbio. A eficiência do processo depende, dentre outros fatores, da capacidade de floculação da biomassa ativa e da composição dos flocos formados.

Os flocos biológicos constituem um micro-sistema complexo formado por bactérias, fungos, protozoários e micrometazoários. As bactérias são as principais responsáveis pela depuração da matéria carbonácea e pela estruturação dos flocos. Entretanto, os componentes da microfauna (protozoários e micrometazoários) também têm importante papel na manutenção de uma comunidade bacteriana equilibrada, na remoção de E. coli, na redução da $\mathrm{DBO}_{5}$ e na floculação. Por serem extremamente sensíveis às alteraçóes no processo, os componentes da microfauna alternam-se no sistema em resposta às mudanças nas condiçôes físico-químicas e ambientais. Desse modo, a composição da microfauna do lodo ativado revela tendências do processo, quanto a eficiência da remoção da demanda bioquímica de oxigênio- $\mathrm{DBO}_{5}$; a eficiência da remoção de sólidos suspensos - SS; as condiçōes de sedimentação do lodo; o nível de aeração empregado no sistema; a presença de compostos tóxicos, tais como metais pesados e amônia; além de poder indicar a ocorrência de sobrecargas orgânicas e de nitrificação (Gerardi, 1986; Hoffmann e Platzer, 2000).

A grande maioria dos autores, dentre eles Jenkins et al (1993), Madoni (1994), Figueiredo et al (1997) e Bento et al (2000) agrupam a microfauna presente no lodo ativado conforme especificado na Tabela 1.

Ao longo dos anos alguns modelos, baseados nas características biológicas do lodo, foram propostos para a verificação das condiçôes operacionais e a avaliação da eficiência dos sistemas de lodos ativados. Dentre estes, destacam-se o modelo criado por Madoni (1994), por De Marco et al (1991) e Bedgoni et al (1991).

De Marco et al (1991) classificaram as estaçôes de tratamento por lodos ativados, baseado na densidade total dos protozoários presentes no tanque de aeração, em 3 categorias:

(a) Sistemas ineficientes: aqueles com aproximadamente 10 organismos/mL;

(b) Sistemas pouco eficientes: aqueles com densidades de $10-10^{3}$ organis$\mathrm{mos} / \mathrm{mL}$;

(c) Sistemas eficientes: aqueles com mais ou $10^{3}$ organismos $/ \mathrm{mL}$.

Segundo Bedgoni (1991), a razão entre a densidade de ciliados predadores de flocos e ciliados fixos está associada à eficiência do tratamento. Quando a razão é maior ou igual a 0,5 , um efluente de melhor qualidade é obtido.

Madoni (1994) correlacionou condiçóes operacionais e os protozoários encontrados nos tanques de aeração de 44 ETEs por lodos ativados, após 20 anos de estudos, definindo grupos positivos e negativos relacionados à eficiência depurativa dos sistemas. $\mathrm{O}$ autor agrupou os CPFs, CFs e TAMBs como positivos e os pequenos flagelados, os CLNs, Vorticella microstoma e Opercularia spp como negativos. A partir deste estudo, o mesmo autor desenvolveu uma matriz de correlação para obtenção do Índice Biótico do Lodo - IBL relacionado às características do sistema. A determinação do IBL baseia-se em relaçôes entre os grupos positivos e os negativos, considerando-se a

Tabela I - Classificação utilizada para agrupar os organismos da microfauna

\begin{tabular}{|c|c|c|}
\hline Grupos & Classificação & Breve descrição \\
\hline \multirow[t]{3}{*}{ Ciliados } & Ciliados predadores de flocos - CPF & $\begin{array}{l}\text { Possuem a célula achatada dorsoventralmente e cílios } \\
\text { modificados e agrupados na parte do corpo que fica em } \\
\text { contato com o substrato. São vorazes predadores de } \\
\text { bactérias. }\end{array}$ \\
\hline & Ciliados Livre Natantes - CLN & $\begin{array}{l}\text { Possuem cílios distribuídos regularmente por toda a } \\
\text { célula e nadam livremente entre os flocos. São predadores } \\
\text { e carnívoros. }\end{array}$ \\
\hline & Ciliados Fixos - CF & $\begin{array}{l}\text { Ficam unidos ao substrato por um pedúnculo, sendo } \\
\text { algumas espécies, coloniais. Os cílios encontram-se na } \\
\text { região anterior do corpo, próximo à cavidade oral. }\end{array}$ \\
\hline \multirow[t]{2}{*}{ Amebas } & Tecamebas - TAMB & $\begin{array}{l}\text { Possuem revestimento externo constituído por proteínas, } \\
\text { sílica, calcário, ferro, etc. }\end{array}$ \\
\hline & Amebas nuas - AMN & Não possuem forma definida, têm corpo mole. \\
\hline Flagelados & Zooflagelados - ZFL ou FLG & $\begin{array}{l}\text { São flagelados não pigmentados podendo ter de um a } \\
\text { vários flagelos. Ingerem matéria sólida ou substâncias } \\
\text { orgânicas e inorgânicas dissolvidas. }\end{array}$ \\
\hline Micrometazoários & $\begin{array}{l}\text { Rotíferos, Nematóides, Anelídeos, } \\
\text { Tardigrados - MTZ }\end{array}$ & $\begin{array}{l}\text { São organismos pluricelulares de vários filos. Possuem } \\
\text { lenta taxa de crescimento, sendo a maioria composta } \\
\text { por predadores de bactérias e protozoários. }\end{array}$ \\
\hline
\end{tabular}

Fonte: Adaptado de Figueiredo et al, 1997. 
densidade e o número de unidades taxonômicas presentes no reator. A concentração de pequenos flagelados constitui um parâmetro de grande interferência no cálculo do índice. Os valores do IBL correspondem a uma das 4 classes definidas para classificação das características do lodo e da qualidade do efluente (Tabela 2).

De acordo com Jenkins et al (1993), Madoni (1994) e Figueiredo et al (1997), um bom desempenho do sistema está diretamente relacionado às espécies dominantes no processo, conforme relações descritas nas Tabela 3 .

Em alguns países, como por exemplo, na Alemanha, a análise microscópica do lodo é prescrita legalmente para sistemas de lodos ativados que atendem mais de 10.000 habitantes. O diagnóstico obtido pela microscopia do lodo ativado é utilizado para alterar as características operacionais do sistema, tais como a idade do lodo e a concentração de oxigênio dissolvido no reator (Hoffmann e Platzer, 2000). No Brasil, a maioria dos sistemas de tratamento de esgotos é monitorada e controlada pelas análises físico-químicas. A observação microscópica ainda é um instrumento raro, geralmente realizada em curtos períodos de tempo e seus resultados são, na grande maioria, subutilizados.

O presente trabalho tem como objetivo a caracterização e quantificação da microfauna presente nos tanques de aeração de uma ETE do tipo lodos ativados (sistema Insular de Florianópolis/SC) e sua correlação com os parâmetros físico-químicos e a eficiência do processo. Além disso, os resultados biológicos obtidos são aplicados nos modelos de avaliação préexistentes.

\section{MATERIAIS E MÉTODOS}

Durante o estudo foram realizadas análises microscópicas, bacteriológicas, físico-químicas e das condiçôes operacionais na ETE Insular de Florianópolis/SC, sob responsabilidade da CASAN (Companhia Catarinense de Águas e Saneamento), a qual possui capacidade instalada para atender 150.000 habitantes da Ilha de Santa Catarina, correspondente a uma vazão média afluente de $278 \mathrm{~L} / \mathrm{s}$. A ETE é do tipo Lodos Ativados de Aeração Prolongada sendo constituída por unidades anóxicas (seletores biológicos e câmaras de desnitrificação) antecedendo tanques de aeração de mistura completa.

As amostragens tiveram periodicidade de 15 dias, tendo início em setem-

Tabela 2 - Conversão do IBL em 4 classes de qualidade e respectivas características do sistema

\begin{tabular}{ccc}
\hline Valor do IBL & Classe & Características \\
\hline $8-10$ & I & $\begin{array}{r}\text { Sistema muito bem colonizado com excelente } \\
\text { atividade biológica e ótima performance. }\end{array}$ \\
$6-7$ & II & $\begin{array}{r}\text { Lodo estável e bem colonizado, atividade biológica } \\
\text { em declínio e boa performance. }\end{array}$ \\
$4-5$ & III & $\begin{array}{r}\text { Insuficiente depuração biológica no tanque de } \\
\text { aeração e média performance. }\end{array}$ \\
$0-3$ & IV & Fraca depuração biológica no tanque de aeração e \\
baixa performance.
\end{tabular}

Fonte: Madoni, 1994.

Tabela 3 - Microrganismos indicadores das condições de depuração

\begin{tabular}{|c|c|}
\hline Microrganismos & Características do processo \\
\hline Predominância de flagelados e amebas & $\begin{array}{l}\text { Lodo jovem, característica de início } \\
\text { de operação ou baixa idade do lodo }\end{array}$ \\
\hline Predominância de flagelados & $\begin{array}{c}\text { Deficiência de aeração, má } \\
\text { depuração e sobrecarga orgânica }\end{array}$ \\
\hline $\begin{array}{c}\text { Predominância de ciliados pedunculados } \\
\text { e livres }\end{array}$ & Boas condições de depuração \\
\hline Predominância de Arcella (ameba com teca) & Boa depuração \\
\hline Predominância de Aspidisca costata & Nitrificação \\
\hline Predominância de Trachelophyllum & Alta idade do lodo \\
\hline $\begin{array}{c}\text { Predominância de Vorticella microstoma } \\
\text { (ciliado pedunculado) e baixa concentração } \\
\text { de ciliados livres }\end{array}$ & Efluente de má qualidade \\
\hline $\begin{array}{l}\text { Predominância de anelídeos do gênero } \\
\text { Aeolosoma }\end{array}$ & Excesso de oxigênio dissolvido \\
\hline Predominância de filamentos & Intumescimento do lodo \\
\hline
\end{tabular}

Fonte: Figueiredo et al (1997).

bro de 1999 e término em agosto de 2000. Foram avaliadas amostras pontuais do esgoto afluente e efluente da ETE para verificação da eficiência do processo e amostras pontuais da massa líquida dos tanques de aeração para a avaliação microscópica.

A análise microscópica quantitativa foi realizada com amostras do tanque de aeração, diluídas 10 vezes e dispostas em câmara de Sedwick-Rafter reticulada, com formato retangular $(50 \times 20 \mathrm{~mm})$, profundidade de $1 \mathrm{~mm}$, área de $1.000 \mathrm{~mm}^{2}$, volume útil de $1 \mathrm{~mL}$ e 1.000 retículos de $0,001 \mathrm{~mL}$ de volume. Para cada amostra, identificaram-se e quantificaram-se as espécies da microfauna presentes em 10 retículos, sendo o resultado final, a média de 3 procedimentos. Para cada leitura, preparou-se a câmara de Sedwick e foram contados aleatoriamente 10 retículos, totalizando o volume de $0,01 \mathrm{~mL}$. O resultado de cada leitura foi multiplicado por 100, para caracterizar o número de organismos presentes em $1 \mathrm{~mL}$ de amostra. $\mathrm{O}$ procedimento foi realizado em microscópico óptico triocular invertido (Coleman, modelo XDP-I) aumento de 100 ou 400 vezes.

$\mathrm{Na}$ identificação da microfauna, utilizaram-se chaves descritas por Bick (1972), WPC (1990) e Patterson (1996). A classificação foi efetuada ao nível de gênero. O lodo foi observado qualitativamente pela avaliação da estrutura dos flocos.

Os parâmetros físico-químicos, tais como, potencial hidrogeniônico $-\mathrm{pH}$, alcalinidade, demanda química de oxigênio-DQO, demanda bioquímica de oxigênio - $\mathrm{DBO}_{5}$, sólidos suspensos - SS, sedimentabilidade do lodo - SSd, nitrogênio amoniacal $-\mathrm{N}-\mathrm{NH}_{4}^{+}$, nitrogênio 
nitrito - $\mathrm{N}-\mathrm{NO}_{2}$, nitrogênio nitrato $\mathrm{N}-\mathrm{NO}_{3}{ }^{-}$, turbidez e índice volumétrico do lodo - IVL, assim como os bacteriológicos de colifomes totais e Escherichia coli, seguiram critérios descritos no Standard Methods for Examination of Water and Wastewater (AWWA/WEF, 1995). O nitrogênio amoniacal foi determinado pelo método Nessler (Vogel, 1981), o OD foi mensurado pelo método iodométrico de Winkley modificado com azida sódica (NBR 10559/88 ) e o IVL, calculado conforme descrito por Jenkins et al (1993). A relação A/M (alimento/microrganismo) foi obtida pela relação entre a carga de $\mathrm{DBO}_{5}\left(\mathrm{~g} / \mathrm{m}^{3} / \mathrm{d}\right)$ e a massa de microrganismos no reator $\left(\mathrm{g} / \mathrm{m}^{3} \mathrm{x}\right.$ volume do reator $\mathrm{em} \mathrm{m}^{3}$ ) (von Sperling, 1997).

As correlaçōes entre as variáveis biológicas e as variáveis físico-químicas foram verificadas pelo método de correlação de Pearson, sendo consideradas positivas aquelas que apresentaram o coeficiente de correlação $(r)>0,200$ e negativas ou inversamente correlacionadas aquelas com $\mathrm{r}<-0,200$.

Os resultados microscópicos obtidos foram expressos pela freqüência relativa, abundância, densidade média e também foram avaliados de acordo com os métodos propostos por Madoni (1994), De Marco et al (1991) e Bedgoni (1991).

\section{RESULTADOS E DISCUSSÃO}

Ao longo do período estudado (351 dias), as características estruturais dos flocos biológicos não apresentaram variaçōes significativas, sendo que estes se mantiveram dispersos, fracos com diâmetro variando de pequeno a médio (menores que $100 \mu \mathrm{m}$ ), com presença de poucos ecurtos filamentos de Nocardia spp, raros representantes de Zooglea e fungos (Figura 1). A microfauna foi composta predominantemente por TAMBs e CPFs em freqüência de $100 \%$ e 91\%, respectivamente (Tabela 4). Esses mesmos grupos de organismos apresentaram maior número de indivíduos na comunidade, compondo $40 \%$ e $23 \%$, respectivamente, da densidade média da microfauna (Figura 2).

A freqüência relativa (Tabela 5) mostra que os gêneros Arcella e Euglypha (Figura 3a e 3b) estiveram presentes em todas as amostras em densidades médias de 1.800 indivíduos $/ \mathrm{mL}$, para ambos os gêneros. O ciliado Aspidisca (Figura 3c) foi o terceiro gênero mais freqüente, apresentando $95 \%$ de freqüência e densidade média de 4.600 indivíduos $/ \mathrm{mL}$.

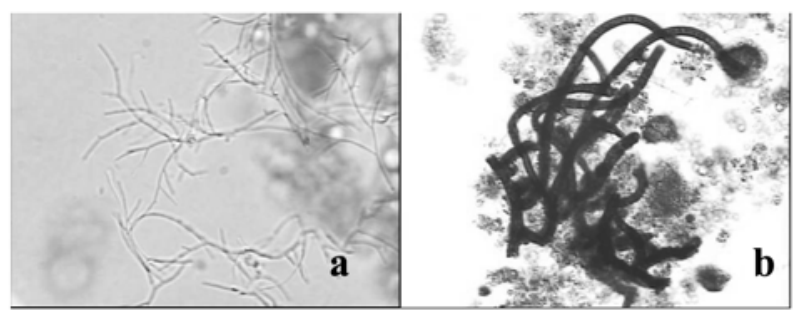

Figura I - Formas filamentosas encontradas nos flocos. (a) Filamentos de Nocardia sp (aumento I.000 vezes) e (b) fungos (aumento 100 vezes)

Tabela 4 - Freqüência relativa dos grupos componentes da microfauna junto ao tanque de aeração

\begin{tabular}{cc}
\hline Grupo & Freqëncia (\%) \\
\hline Tecamebas - TAMBs & 100 \\
Ciliados predadores de flocos - CPFs & 91 \\
Ciliados livre-natantes - CLNs & 70 \\
Ciliados fixos - CFs & 66 \\
Zooflagelados - ZFLGs & 69 \\
Micrometazoários - MTZs & 86 \\
\hline
\end{tabular}
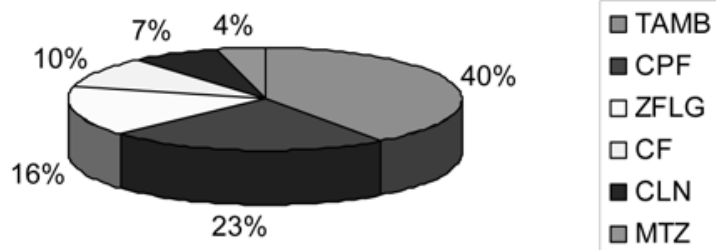

Figura 2 - Abundância relativa dos grupos da microfauna

Os pequenos ZFLGs, juntamente com Aspidisca, apresentaram densidades notadamente maiores no período de 25/04/00 a 08/08/00, quando também se observou o surgimento dos CFs Thuricola sp (Figura 4a) e Vaginicolla sp. Neste mesmo período ocorreram as menores temperaturas atmosféricas, atingindo $14^{\circ} \mathrm{C}$. Os MTZs foram visualizados em baixa densidade, mas em elevada freqüência, principalmente os rotíferos (Figura $4 \mathrm{~b}$ ), indicando uma elevada idade do lodo. Dentre os ciliados fixos, Vorticella sp (Figura 4c) apresentou maior freqüência, mas também menor densidade em relação aos demais.

O número de indivíduos da microfauna variou de 4.750 indivíduos $/ \mathrm{mL}$ a 53.010 indivíduos $/ \mathrm{mL}$, sendo que as maiores densidades ocorreram nos períodos de novembro a dezembro de 1999, com média de 32.427 indivíduos $/ \mathrm{mL}$ maio a agosto de 2000 , média de 28.645 indivíduos $/ \mathrm{mL}$. As reduçôes de $\mathrm{DQO}, \mathrm{DBO}_{5}$ e E. coli apresentaram correlaçôes positivas com a densidade total de organismos no reator, indicando que quanto maior a densidade de organismos, maior a remoção destes parâmetros no sistema (Tabela 6). Vários autores (Curds, 1975; De Marco et al, 1991; Madoni, 1994) obtiveram as mesmas correlaçōes. A redução de bactérias E. coli deve-se à predação exercida pelos protozoários. Nos sistemas de lodos ativados o reduzido tempo de detenção hidráulica não favorece o declínio bacteriano de $E$. coli, portanto, os fatores preponderantes na remoção destas bactérias são a predação exercida pela microfauna além de sua aderência aos flocos biológicos. Curds (1975), após inúmeros experimentos, concluiu que a presença de protozoários em sistemas reduz mais que $99 \%$ das bactérias do grupo coliformes fecais. 
Tabela 5 - Freqüência relativa e densidade média dos gêneros da microfauna encontrados no sistema, durante o estudo

\begin{tabular}{|c|c|c|c|}
\hline Grupo & G?enero & $\begin{array}{c}\text { Freqüência } \\
(\%)\end{array}$ & $\begin{array}{c}\text { Média } \\
\text { (indivíduos } / \mathrm{mL} \text { ) }\end{array}$ \\
\hline \multirow[t]{3}{*}{$\mathrm{CPF}$} & Aspidisca & 95 & 460 \\
\hline & Euplotes & 50 & 490 \\
\hline & Chilodonella & 30 & 590 \\
\hline \multirow[t]{7}{*}{ CLN } & Blepharisma & 15 & 190 \\
\hline & Paramecium & 10 & 140 \\
\hline & NI & 15 & 730 \\
\hline & Trachelophylum & 75 & 1110 \\
\hline & Chaetospira & 30 & 360 \\
\hline & Colpoda & 5 & 840 \\
\hline & Tetrahymena & 5 & 490 \\
\hline \multirow[t]{4}{*}{ CF } & Vorticella & 50 & 460 \\
\hline & Epistylis & 20 & 1820 \\
\hline & Opercularia & 10 & 2280 \\
\hline & Vaginicola e Thuricola & 35 & 3780 \\
\hline \multirow[t]{3}{*}{ CF - carnívoros } & Acineta & 15 & 260 \\
\hline & Tokophrya & 10 & 170 \\
\hline & Podophrya & 10 & 60 \\
\hline \multirow[t]{3}{*}{ ZFLG } & Bodo & 20 & 7410 \\
\hline & Peranema & 40 & 490 \\
\hline & $\mathrm{NI}$ & 50 & 8050 \\
\hline \multirow[t]{6}{*}{ TAMB } & Arcella & 100 & 1810 \\
\hline & Centropyxis & 70 & 1420 \\
\hline & Euglypha & 100 & 1790 \\
\hline & Diffugia & 20 & 5010 \\
\hline & Diolophrys & 5 & 330 \\
\hline & Quadruella & 15 & 1650 \\
\hline \multirow[t]{3}{*}{$\mathrm{AMB}$} & Amebas nuas & 20 & 4620 \\
\hline & Rotíferos & 80 & 410 \\
\hline & Tardígrados & 55 & 120 \\
\hline \multirow[t]{3}{*}{ MTZ } & Nematóide & 5 & 80 \\
\hline & Aelossoma & 30 & 410 \\
\hline & NI & 10 & 140 \\
\hline
\end{tabular}

Convençōes: CPF - Ciliados Predadores de Flocos; CLN - Ciliados Livre-Natantes; CF - Ciliados Fixos; ZFLG - Zooflagelados; TAMB = Tecamebas; AMB - Amebas; MTZ - Micrometazoários; NI = Não identificado 
As concentrações de SS e a turbidez no efluente apresentaram relação diretamente proporcional com a densidade total da microfauna. Quanto maior a densidade de organismos nos reatores, maior também a concentração de sólidos no efluente. Provavelmente, os ZFGLs são os responsáveis por essa condição, pois estes organismos não se agregam aos flocos e por isso, saem do sistema junto com o efluente final. Em estudo realizado por Madoni (1994), relações similares foram verificadas, mas, geralmente, associadas à queda da eficiência depurativa do sistema, fato este não verificado na ETE durante o período estudado.

As correlaçôes entre a densidade dos grupos da microfauna presentes nos reatores do sistema e os demais parâmetros encontram-se descritas na Tabela 7. As correlaçôes negativas para as concentraçôes de $\mathrm{DQO}$ e $\mathrm{DBO}_{5}$ no efluente coincidem para os CPFs, CFs e ZFLGs, significando que as maiores remoçóes de DQO e $\mathrm{DBO}_{5}$ ocorreram quando os organismos pertencentes a esses 3 grupos foram mais abundantes. Esse fato era esperado para os CPFs e ps CFs, os quais contribuem para a redução do material particulado, não integrante dos flocos. Entretanto, para os ZFLGs esta relação deveria ser inversa e não proporcional, pois estes organismos não se aderem ao floco, são eliminados no efluente final e desenvolvem-se no sistema em presença de material orgânico dissolvido. A possível explicação para esta constatação pode residir na presença do grande ZFLG Peranema sp no sistema, além dos pequenos flagelados, sendo que os estudos realizados apontam apenas os segundos como indicadores de baixa eficiência depurativa.

$\mathrm{A} \mathrm{DBO}_{5}$ efluente apresentou relação inversa à densidade de CPFs, CFs, ZFLGs e CLNs, e diretamente proporcional às densidades de TAMBs e MTZs. Jardim et al (1997) observaram correlações semelhantes para os CLNs e ZFLGs eTAMBs. Porém, para os MTZs os autores verificaram o oposto, menores concentraçôes de $\mathrm{DBO}_{5}$ efluente quando a densidade de MTZs no tanque de aeração era maior.

As concentrações de SS e a turbidez do efluente foram diretamente proporcionais às densidades de TAMBs e ZFLGs $\mathrm{e}$, inversamente proporcionais à densidade de CLNs, o que coincide com as observações feitas por Madoni (1994). Os ZFLGs são os protozoários mais citados como indicadores de efluente com eleva-

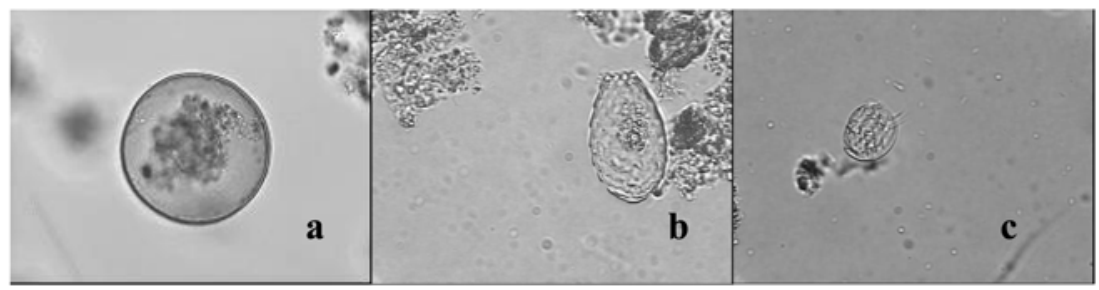

Figura 3 - Protozoários presentes em maior freqüência na ETE em estudo. (a) Arcella sp (aumento de 400 vezes), imagem capturada pela bióloga Vanessa Cataneo, (b) Euglypha sp (aumento de 400 vezes) e (c) Aspidisca sp (aumento de 400 vezes)

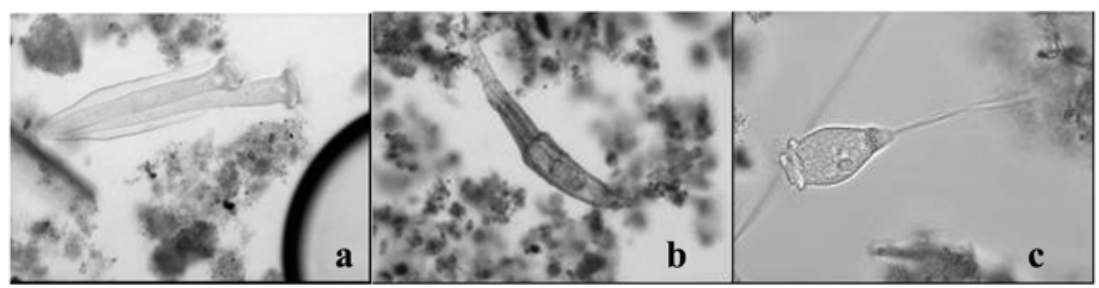

Figura 4 - Ciliados fixos e rotíferos presentes no lodo. (a) Thuricola sp (aumento de 200 vezes), (b) rotífero (aumento de 200 vezes),

(c) Vorticella sp (aumento de 200 vezes). Imagens capturadas pela bióloga Vanessa Cataneo

Tabela 6 - Correlação entre densidade total da microfauna nos reatores e parâmetros físico-químicos, operacionais e bacteriológicos

\begin{tabular}{cc}
\hline Parâmetro & Correlação \\
\hline $\mathrm{DQO}(\%$ remoção) & + \\
$\mathrm{DBO}_{5}(\%$ remoção) & + \\
$\mathrm{N}^{-\mathrm{NH}_{4}^{+}}$(\% remoção) & 0 \\
$\mathrm{SS}($ concentração no efluente) & + \\
Turbidez (efluente) & + \\
E. coli (remoção - log) & 0 \\
$\mathrm{IVL}$ (tanque de aeração) & - \\
pH (tanque de aeração) & - \\
SSd (tanque de aeração) & -
\end{tabular}

Convençôes: +: correlação positiva (diretamente proporcional); -: correlação negativa (inversamente proporcional) e 0: correlação nula (sem correlação).

da concentração de $\mathrm{SS}$ e $\mathrm{DBO}_{5}$. Da mesma forma, esses protozoários apresentaram correlaçóes significativas com o IVL, podendo-se sugerir sua indicação para sistemas com problemas na sedimentação do lodo.

A ocorrência e densidade de MTZs estiveram diretamente relacionadas com o IVL, indicando que os maiores índices ocorreram quando maiores densidades de MTZs foram observadas. Os MTZs apresentam lenta taxa de crescimento e reprodução e por isso indicam alto tempo de detenção celular. Dessa forma, para a ETE Insular, pode-se relacionar as maiores idades do lodo com maiores valores de IVL.

Pela correlação de Pearson os únicos organismos que apresentaram relação com a concentração de $\mathrm{N}-\mathrm{NH}_{4}^{+}$no efluente foram os CPFs. Para o N-NO ${ }_{3}^{-}$observaram-se correlaçóes negativas com os CLNs e os CPFs. Através desta análise, pode-se sugerir que a nitrificação apresentou relação com a densidade de CPF no reator, ou seja, quanto maior a densidade desses organismos, menor a taxa de nitrificação 
Tabela 7 - Correlação entre a densidade dos grupos da microfauna e os parâmetros físico-químicos e bacteriológicos

\begin{tabular}{ccccccc}
\hline Parâmetros & CPF & CLN & CF & TAMB & ZFLG & MTZ \\
\hline DQO efluente $(\mathrm{mg} / \mathrm{L})$ & - & 0 & - & 0 & - & - \\
pH no tanque de aeração & - & + & 0 & 0 & - & 0 \\
Temperatura da amostra & - & 0 & 0 & 0 & - & 0 \\
$\mathrm{~N}_{-} \mathrm{NH}_{4}^{+}$no efluente & + & 0 & 0 & 0 & 0 & 0 \\
$\mathrm{DBO}_{5}$ efluente $(\mathrm{mg} / \mathrm{L})$ & - & - & - & + & - & + \\
$\mathrm{SS}_{\text {no efluente }}$ & + & - & 0 & + & + & 0 \\
Turbidez no efluente $_{\text {IVL }}$ & 0 & - & 0 & - & 0 & 0 \\
E. colino efluente & - & - & 0 & 0 & + & - \\
SSd & + & + & + & - & + & - \\
$\mathrm{N}-\mathrm{NO}_{3}^{-}$no efluente & - & - & 0 & 0 & 0 & 0 \\
\hline
\end{tabular}

Convençôes - CPF: Ciliados Predadores de Flocos; CLN: Ciliados Livre-Natantes; CF: Ciliados Fixos; ZFLG: Zooflagelados; TAMB: Tecamebas; AMB: Amebas; MTZ: Micrometazoários; +: correlação positiva (diretamente proporcional); -: correlação negativa (inversamente proporcional) e 0: correlação nula (sem correlação).

(maiores concentrações de $\mathrm{N}-\mathrm{NH}_{4}^{+}$e menores concentrações de $\mathrm{N}_{-} \mathrm{NO}_{3}{ }^{-}$no efluente).

Apesar de não se ter conhecimentos mais específicos sobre as relaçóes entre a microfauna e o processo de nitrificação, autores como Jardim et al (1997) e Cybis et al (1997) observaram correlaçōes entre a ocorrência de nitrificação e a presença de CFs no reator. Jenkins et al (1993) relacionaram a presença de nematóides e tardígrados com a ocorrência de nitrificação no sistema, pois esses organismos apresentam extrema sensibilidade à presença de amônia. Entretanto, pelo método de correlação de Pearson, essas relações não foram verificadas neste estudo.

$\mathrm{Na}$ Tabela 8 pode-se observar a aplicação dos métodos de Madoni (1994), De Marco et al (1991) e Bedgoni (1991), os quais baseiam-se no IBL, na densidade total da microfauna e na relação $\mathrm{CPF} / \mathrm{CF}$, respectivamente, na caracterização da ETE Insular.

De acordo com o IBL o sistema apresentou média, boa e excelente performance em $20 \%$, 35\% e $45 \%$ do período avaliado, respectivamente. Algumas das amostragens com menores índices coincidem com maiores concentrações de $\mathrm{DBO}_{5}$ no efluente. A avaliação da ETE, segundo De Marco (1991), indicou que o sistema apresentou excelente eficiência durante todo o período, pois a densidade da microfauna foi superior a 1.000 indivíduos/mL em todas as amostragens. Pela relação proposta por Bedgoni (1991), o sistema foi muito eficiente durante todo o estudo, exceto em uma amostragem (06/06/00). Neste mesmo dia, verificouse a maior $\mathrm{DBO}_{5}$ no efluente da ETE $(20 \mathrm{mg} / \mathrm{L})$.

As relações entre os microrganismos dominantes no lodo e o seu significado no sistema, conforme literatura especializada, encontram-se descritas na Tabela 9, juntamente com as concentrações de $\mathrm{DBO}_{5}$ e N-NH${ }_{4}^{+}$no esgoto tratado. Observa-se que na maior parte do período, a microfauna dominante nos reatores indicou boas condiçōes de depuração e a ocorrência da nitrificação. Os períodos de média e baixa eficiência estiveram associados, principalmente, à dominância de ZFLGs e CFs (Epistylis e Vaginicola) e os períodos de alta eficiência, associados à presença de TAMBs e CPFs.

As características do processo, presumidas pelos organismos dominantes nos reatores, revelaram que na maioria do período estudado o sistema apresentou alta idade do lodo, indicada principalmente pela presença de TAMBs, Trachellophylum (Figura 5a) e MTZs; baixa relação A/M, evidenciada por Nocardia spp, ocorrência de nitrificação verificada pela presença de Aspidisca e Tardígrados (Figura 5b). Os menores desempenhos foram associados à presença dominante de pequenos ZFLGs e CFs. Em algumas amostragens a dominância ou co-dominância de ZFLG não alterou a qualidade do efluente. Associa-se a esse fato a detecção do grande flagelado Peranema sp e não somente das espécies de tamanho pequeno, citadas em literatura como bioindicadoras de baixo desempenho em sistemas de lodos ativados.

As análises físico-químicas evidenciaram que a ETE Insular apresentou excelente performance durante todo o período de estudo, com elevada remoção de matéria orgânica carbonácea e ocorrência de nitrificação e provável desnitrificação (Tabela 10).

Os resultados apresentados na Tabela 10 revelam a boa eficiência do sistema estudado, indicando que as informações obtidas pelas análises microscópicas, de uma maneira geral, forneceram uma indicação correta acerca da performance do tratamento.

\section{CONCLUSÕES}

Com base no estudo microscópico realizado junto à ETE Insular de Florianópolis/SC (do tipo lodos ativados de aeração prolongada) e aplicando-o como método de avaliação do sistema, conclui-se:

- A presença de filamentos de Nocardia sp, flocos pequenos, Arcella sp e Euglypha sp indicou que a ETE estudada trabalha com baixa relação $\mathrm{A} / \mathrm{M}$, o que pode ser comprovado pelas análises físico-químicas da ETE (aproximadamente 0,032 kg DBO $/ \mathrm{kgSSV} / \mathrm{d}$ );

- As remoções médias de $97 \%$ de $\mathrm{DBO}_{5}, 80 \%$ de DQO e $96 \%$ de $\mathrm{N}-\mathrm{NH}_{4}$ foram associadas à presença constante de Arcella, Euglypha sp e Aspidisca sp;

- A ocorrência de Arcella sp, Euglypha sp e Aspidisca sp em freqüências de $100 \%$ para as duas primeiras e $95 \%$ para a última indicaram alto grau de estabilidade biológica do sistema, alta idade do lodo, boas remoções de $\mathrm{DBO}_{5}$ e condições de oxigenação favoráveis à nitrificação;

- Os micrometazoários e as tecamebas indicaram alto tempo de detenção celular no processo (idade do lodo maior que 20 dias);

- A presença de zooflagelados em densidades superiores a $1,0 \times 10^{4}$ indivíduos $/ \mathrm{mL}$ indicaram lodo com densidade elevada (IVL > $100 \mathrm{~mL} / \mathrm{g}$ ) e baixa condição de sedimentabilidade $(\mathrm{SSd}>800 \mathrm{~mL} / \mathrm{L})$;

- As maiores densidades da microfauna nos reatores implicaram em melhores reduções de $\mathrm{DBO}_{5}, \mathrm{DQO}$ e E. coli, porém, maiores concentraçôes de SS e turbidez no efluente; 
Tabela 8 - Aplicação do IBL, da densidade total da microfauna e da relação CPF/CF para classificação da ETE Insular

\begin{tabular}{lccc}
\hline Amostragem & IBL & $\begin{array}{c}\text { Densidade da microfauna } \\
\text { (organimos/mL) }\end{array}$ & CPF/CF \\
\hline $01(28 / 09 / 99)$ & 7 & 10,750 & - \\
$02(25 / 10 / 99)$ & 9 & 16.620 & 0,8 \\
$03(11 / 11 / 99)$ & 8 & 45.340 & 2,8 \\
$04(22 / 11 / 99)$ & 7 & 53.010 & 2,3 \\
$05(08 / 12 / 99)$ & 8 & 15.710 & 2,3 \\
$06(20 / 12 / 99)$ & 10 & 15.650 & 45,1 \\
$07(03 / 01 / 00)$ & 7 & 8.800 & 0,9 \\
$08(26 / 01 / 00)$ & 7 & 10.560 & 0,5 \\
$09(08 / 02 / 00)$ & 9 & 11.940 & 1,3 \\
$10(29 / 02 / 00)$ & 7 & 10.610 & 3,2 \\
$11(14 / 03 / 00)$ & 8 & 9.100 & 11,0 \\
$12(21 / 03 / 00)$ & 8 & 8.390 & 0,7 \\
$13(04 / 04 / 00)$ & 9 & 4.750 & 4,9 \\
$14(25 / 04 / 00)$ & 8 & 29.880 & 0,9 \\
$15(09 / 05 / 00)$ & 4 & 25.350 & 0,6 \\
$16(06 / 06 / 00)$ & 4 & 16.440 & 0,4 \\
$17(20 / 06 / 00)$ & 4 & 30.710 & 3,3 \\
$18(04 / 07 / 00)$ & 7 & 32.100 & 7,5 \\
$19(18 / 07 / 00)$ & 7 & 25.800 & 4,6 \\
$20(08 / 08 / 00)$ & 4 & 41.470 & 3,8 \\
Média & 7,3 & 21.150 & 5 \\
\hline
\end{tabular}

Convençôes: IBL: Índice Biótico do Lodo; CPF/CF: Relação entre Ciliados Predadores de Flocos e Ciliados Fixos.

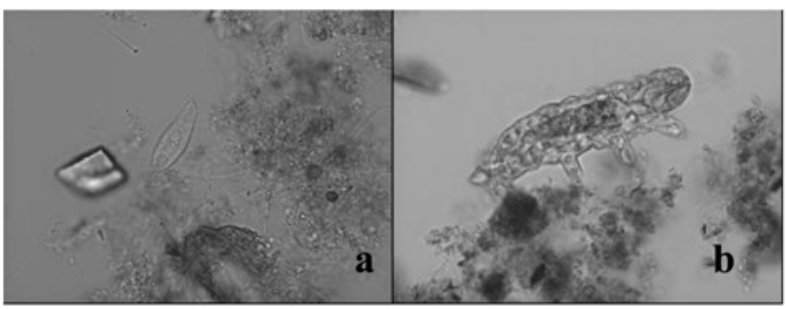

Figura 5 - Organismos indicadores de alta idade do lodo. (a) Trachellophylum sp (aumento de 400 vezes) e (b) tardígrado (aumento de 200 vezes). Imagens capturadas pela bióloga Vanessa Cataneo 
Tabela 9 - Relação entre os microrganismos encontrados no sistema e as características do processo, segundo Vazollér et al ( 1989), Jenkins et al (1993), Madoni ( 1994 ), Di Marzio et al ( 1999 ) e concentrações de DBO e N-NH no efluente da ETE insular

\begin{tabular}{|c|c|c|c|c|}
\hline Amostragem & Microrganimos dominantes & Características do processo & $\begin{array}{l}\mathrm{DBO}_{5} \\
(\mathrm{mg} / \mathrm{L})\end{array}$ & $\begin{array}{c}\mathrm{N}-\mathrm{NH}_{4} \\
(\mathrm{mg} / \mathrm{L})\end{array}$ \\
\hline $01(28 / 09 / 99)$ & Aspidisca, Arcella & $\begin{array}{l}\text { Ocorrência de nitrificação; boa remoção de } \mathrm{DBO}_{5} \text {. Alta } \\
\text { idade do lodo e baixa carga aplicada }\end{array}$ & 11 & 0,8 \\
\hline $02(25 / 10 / 99)$ & Epistylis, Aspidisca, rotíferos & Transição biológica, desempenho decrescendo & 11 & 0,9 \\
\hline $03(11 / 11 / 99)$ & $\begin{array}{c}\text { Amebas nuas, Centropyxis, } \\
\text { Aspidisca }\end{array}$ & $\begin{array}{l}\text { Médio desempenho. Elevada concentração de compostos } \\
\text { de difícil degradação ou choques de carga }\end{array}$ & 8 & 0,9 \\
\hline $04(22 / 11 / 99)$ & Diffugia, zooflagelados & $\begin{array}{l}\text { Médio desempenho. Baixa carga, choque de carga ou } \\
\text { presença de subprodutos da fermentação }\end{array}$ & 15 & 0,9 \\
\hline $05(08 / 12 / 99)$ & Aspidisca, Arcella & $\begin{array}{l}\text { Ocorrência de nitrificação; boa remoção de } \mathrm{DBO}_{5} \text {. Alta } \\
\text { idade do lodo e baixa carga aplicada }\end{array}$ & 5 & 0,6 \\
\hline $06(20 / 12 / 99)$ & Aspidisca, Arcella & $\begin{array}{l}\text { Ocorrência de nitrificação; boa remoção de } \mathrm{DBO}_{5} \text {. Alta } \\
\text { idade do lodo e baixa carga aplicada }\end{array}$ & 5 & 0,2 \\
\hline $07(03 / 01 / 00)$ & Arcella, Aspidisca & $\begin{array}{l}\text { Ocorrência de nitrificação boa remoção de } \mathrm{DBO}_{5} \text {. Alta } \\
\text { idade do lodo e baixa carga aplicada }\end{array}$ & 8 & 0,3 \\
\hline $08(26 / 01 / 00)$ & Euglypha, Arcella & $\begin{array}{l}\text { Boas condiçôes de depuração. Baixa relação } \mathrm{A} / \mathrm{M} \text {, alta } \\
\text { idade do lodo }\end{array}$ & 20 & 1,0 \\
\hline $09(08 / 02 / 00)$ & Euglypha, Quadruella & $\begin{array}{l}\text { Boas condiçôes de depuração. Baixa relação A/M, alta } \\
\text { idade do lodo }\end{array}$ & 4 & 1,7 \\
\hline $10(29 / 02 / 00)$ & Euglypha, Quadruella & $\begin{array}{l}\text { Boas condições de depuração. Baixa relação A/M, alta } \\
\text { idade do lodo }\end{array}$ & 16 & 1,1 \\
\hline $11(14 / 03 / 00)$ & $\begin{array}{l}\text { Trachelophylum, Aspidisca, } \\
\text { Arcella }\end{array}$ & $\begin{array}{l}\text { Boas condiçôes de depuração. Ocorrência de nitrificação. } \\
\text { Elevada idade do lodo, baixa relação A/M }\end{array}$ & 5 & 0,9 \\
\hline $12(21 / 03 / 00)$ & Trachelophylum, Arcella & Boa depuração. Alta idade do lodo e baixa carga & 6 & 0,2 \\
\hline $13(04 / 04 / 00)$ & Euglypha, Chilodonela & Boas condiçōes de depuração & 5 & 0,5 \\
\hline $14(25 / 04 / 00)$ & Vaginicola, Aspidisca & $\begin{array}{l}\text { Média depuração, efluente de elevada turbidez. Transição } \\
\text { biológica }\end{array}$ & 4 & 0,4 \\
\hline $15(09 / 05 / 00)$ & Zooflagelados, Vaginicola & $\begin{array}{l}\text { Fraco desempenho, alta carga de compostos de difícil } \\
\text { degradação. Alto tempo de detenção celular }\end{array}$ & 3 & ND \\
\hline $16(06 / 06 / 00)$ & Zooflagelados, Vaginicola & $\begin{array}{l}\text { Fraco desempenho, alta carga de compostos de difícil } \\
\text { degradação. Alto tempo de detenção celular }\end{array}$ & 14 & 0,4 \\
\hline $17(20 / 06 / 00)$ & Zooflagelados, Aspidisca & Médio desempenho. Transição biológica & 3 & 2,0 \\
\hline $18(04 / 07 / 00)$ & Aspidisca, zooflagelados & Médio desempenho. Transição biológica & 6 & 0,8 \\
\hline $19(18 / 07 / 00)$ & Aspidisca, zooflagelados & Médio desempenho. Transição biológica & 3 & 5,7 \\
\hline $20(08 / 08 / 00)$ & Zooflagelados, Aspidisca & Fraco desempenho. Muito material dissolvido no efluente & 2 & 0,9 \\
\hline
\end{tabular}

Convenção: ND = Não detectável pelo método. 
Tabela 10 - Concentrações e remoções médias dos principais parâmetros avaliados na ETE Insular durante o período compreendido entre setembro de 1999 e agosto de 2000

\begin{tabular}{cccc}
\hline Parâmetro & $\begin{array}{c}\text { Esgoto afluente } \\
\text { (concentração mg/L) }\end{array}$ & $\begin{array}{c}\text { Esgoto efluente } \\
\text { (concentração mg/L) }\end{array}$ & $\begin{array}{c}\text { Remoção } \\
(\%)\end{array}$ \\
\hline $\mathrm{DQO}$ & $438 \pm 109$ & $78 \pm 22$ & $80 \pm 13$ \\
$\mathrm{DBO}_{5}$ & $203,1 \pm 53,7$ & $7,1 \pm 3,7$ & $97 \pm 2$ \\
$\mathrm{~N}_{5} \mathrm{NH}_{4}$ & $28,7 \pm 5,4$ & $1,0 \pm 0,7$ & $96 \pm 7$ \\
$\mathrm{~N}^{-} \mathrm{NO}_{3}^{-}$ & - & $8,1 \pm 2,8$ & - \\
$\mathrm{SS}^{-}$ & $284 \pm 160$ & $69 \pm 37$ & $74 \pm 22$ \\
\hline
\end{tabular}

- O IBL, a razão entre CPF/CF e a densidade da microfauna apresentaramse eficientes como instrumentos de diagnóstico das condiçōes depurativas do sistema, sendo que os dois últimos métodos foram mais precisos;

- As análises microscópicas qualitativas apresentaram-se suficientes para uma caracterização imediata das condiçōes depurativas do processo;

- A análise qualitativa do lodo, englobando os aspectos gerais dos flocos (tamanho, quantidade de filamentos, compactação, etc.) e a identificação das espécies dominantes, foi suficiente para uma caracterização imediata das condiçôes depurativas do sistema de tratamento;

- Na análise qualitativa éimportante a avaliação global e sistêmica do lodo. A presença de uma única espécie da microfauna muitas vezes não deve ser utilizada como indicativo da performance do processo. Para a ETE Insular a presença e abundância de zooflagelados em algumas amostragens não pôde ser relacionada com a redução da qualidade do efluente produzido no sistema.

\section{AGRADECIMENTOS}

Os autores gostariam de agradecer a Companhia Catarinense de Águas e Saneamento - CASAN e ao Programa de Pós-graduação em Engenharia Sanitária e Ambiental-PPGEA, da Universidade Federal de Santa Catarina, pela viabilização das condições necessárias à execução desse estudo.

\section{REFERÊNCIAS}

AWWA - WEF. Standard methods for the examination of water and wastewater. $19^{\text {th }}$ ed. Washington: APHA. 1134p. 1995.

BEDOGNI, G., FALANELLI, A., PEDRAZZI, R. Evaluation of the abundance ratio between crawling and attached ciliates in the management of an activated sludge sewage treatment plant. In: BIOLOGICAL APPROACH TO SEWAGE TREATMENT PROCESS: CURRENT STATUS AND PERSPECTIVES, Perugia. Proceedings. Perugia: Centro Bazzucchi, p. 229-233. 1991.

BENTO, A.P., PHILIPPI, L.S. Caracterização da microfauna na avaliação da remoção de nitrogênio e matéria orgânica em um sistema de tratamento por lodos ativados. In: IX SIMPÓSIO LUSO-BRASILEIRO DE ENGENHARIA SANITÁRIA E AMBIENTAL, Porto Seguro, Anais... ABES, p.678-687. 2000.

BICK. H. Ciliated Protozoa. 1 ed. Geneva: World Health Organization, 199 p. 1972.

CURDS, C.R. Protozoa. In: ECOLOGICAL ASPECTS OF USE WATER TREATMENT. London, London, Proceedings... London: Academic Press., p. 203-268. 1975.

CYBIS, L.F., PINTO, C.R.R. Protozoários e metazoários presentes em reatores sequenciais em batelada (RSB) observados no processo de nitrificação. In: $19^{\circ}$ CONGRESSO BRASILEIRO DE ENGENHARIA SANITÁRIA E AMBIENTAL, Anais... Fóz do Iguaçu: ABES, p. 793-802. 1997.

De MARCO, N. et al. Performance of biological sewage treatment plants: some experiences on municipal plants in the province of Pordinone (Italy). In: BIOLOGICAL APPROACH TO SEWAGE TREATMENT PROCESS: CURRENT STATUS AND PERSPECTIVES, Proceedings... Perugia: Centro Bazzucchi, p. 247-251. 1991.

Di MARZIO, W.D. et al. Indicadores microbiológicos del funcionamiento de sistemas industriales de depuración por lodos activados de la provincia de Buenos Aires, Argentina. In: CONGRESO MUNDIAL DEL ÁGUA, Anais... Argentina: AIDIS, p. 94-100. 1999.

FIGUEIREDO, M. G.; DOMINGUES, V. B. Microbiologia de Lodos Ativados. CETESB Companhia de Tecnologia de Saneamento Ambiental.. São Paulo: CETESB, 48 p. 1997.

GERARDI, M.H. An operator's guide to protozoa and their role in the activated sludge process. Public Works, p. 44-47/90-92, July. 1986.

HOFFMANN, H., PLATZER, C. Aplicação de imagens microscópicas do lodo ativado para a detecção de problemas de funcionamento das estaçôes de tratamento de esgotos na Alemanha. In: I SEMINÁRIO DE MICROBIOLOGIA APLICADA AO SANEAMENTO, Anais... Universidade Federal do Espírito Santo, p. $108-120.2000$.
JARDIM, F.A., BRAGA, J.M.S., MESQUITA, M.M.F. Avaliação da eficiência do tratamento biológico de esgotos através da caracterização da microbiota da ETE Fonte Grande Contagem-MG. In: $19^{\circ}$ CONGRESSO BRASILEIRO DE EGENHARIA SANITÁRIA E AMBIENTAL, Anais... Fóz do Iguaçu: ABES, p. 1-12. 1997.

JENKINS, D., RICHARD, M.G., DAIGGER, G.T. Manual on the Causes and Control of Activated Sludge Bulking and Foaming. 2 ed. Chelsea, Michigan: Lewis Publishers, Inc., 193 p. 1993.

MADONI, P. A., Sludge biotic index (SBI) for the evaluation of the biological performance of activated sludge plants based on the microfauna analysis. Water Research, v. 28, n. 1, p. 67-75, 1994.

NBR 10559/88 - Águas - Determinação de oxigênio dissolvido - Método iodométrico de Winkley e suas modificaçôes - Método de ensaio.

PATTERSON, D. J. Free-living freshwater Protozoa. Austrália: Universidade de Sydney, 223 p. 1996.

VAZOLLÈR, R. F.; GARCIA, A. D.; CONCEIÇÃO NETO, J. Microbiologia de Lodos Ativados - Série Manuais. CETESB - Companhia de Tecnologia de Saneamento Ambiental. São Paulo: CETESB, 23 p. 1991.

VOGEL, A. L. Análise Inorgânica Qualitativa. 4ed. Editora Guanabara. Rio de Janeiro-RJ. 1981 .

Von SPERLING, M. Lodos Ativados. Belo Horizonte: Departamento de Engenharia Sanitária e Ambiental, Universidade Federal de Minas Gerais, 416 p. 1997.

WPC - Water Pollution Control. Wastewater Biology: The Microlife. Alexandria, Va: Water Environmental Federation, 196 p. 1990.

\section{Endereço para correspondência:}

\section{Alessandra Pellizzaro Bento Universidade Federal de Santa Catarina \\ End.: Rua Aracy Vaz Callado I 735 88090-690 Estreito - Florianópolis - SC - Brasil \\ Tel.: (48) 3244-5432 \\ Email:alessandrabento@gmail.com}

